\title{
Movements of brown smoothhounds, Mustelus henlei, in Tomales Bay, California
}

\author{
Brent R. Campos • Maxfield A. Fish • Gardner Jones • Rebecca W. Riley • \\ Peter J. Allen • Peter A. Klimley • Joseph J. Cech Jr • John T. Kelly
}

Received: 12 October 2007 / Accepted: 2 February 2009/Published online: 4 March 2009

(C) The Author(s) 2009. This article is published with open access at Springerlink.com

\begin{abstract}
Ultrasonic telemetry was used to analyze the effects of environmental variables on movement directions and movement rates of brown smoothhounds, Mustelus henlei, in Tomales Bay, California. Ultrasonic transmitters were surgically implanted in the peritoneal cavities of one male and five female brown smoothhounds and tracked during the period of 29 June to 15 July 2004. Coarse-scale tracking consisted of locating
\end{abstract}

B. R. Campos $(\bowtie) \cdot$ M. A. Fish $\cdot$ G. Jones $\cdot$ R. W. Riley $\cdot$ P. J. Allen • P. A. Klimley · J. J. Cech Jr · J. T. Kelly Department of Wildlife, Fish, and Conservation Biology, University of California, Davis,

One Shields Avenue,

Davis, CA 95616, USA

e-mail: brcampos@gmail.com

Present Address:

B. R. Campos

Department of Wildlife, Humboldt State University,

1 Harpst St,

Arcata, CA 95521, USA

Present Address:

P. J. Allen

Department of Zoology, University of Manitoba Winnipeg, Z320 Duff Roblin Building,

Winnipeg, MB R3T 2N2, Canada

Present Address:

J. T. Kelly

Department of Natural Resources Conservation,

University of Massachusetts,

204 Holdsworth Hall,

Amherst, MA 01003, USA all tagged individuals multiple times during a single session, while fine-scale tracking consisted of following a single individual continuously during a session. Coarse-scale tracking suggested movement toward the inner bay with incoming and high tides and toward the outer bay with outgoing and low tides $(\mathrm{P}=0.01)$, whereas the diel cycle had no apparent effect on their movement directions. Mean shark movement rate was $0.09 \mathrm{~m} \mathrm{~s}^{-1}$ (range: $0.01-0.34 \mathrm{~m} \mathrm{~s}^{-1}$ ), with diel and tidal cycles both having significant effects on their rates of movement $(\mathrm{P}=0.02$ and $P<0.01)$, respectively. We tracked two female sharks on a fine scale over three tracking sessions in July 2004. Both individuals exhibited higher rates of movement during the night compared to the day $(P<0.01)$. While one shark's rate of movement was not significantly affected by tidal stage, the other's was $(P<0.001)$.

Keywords Shark $\cdot$ Mustelus henlei Telemetry Movement · Behavior

\section{Introduction}

The brown smoothhound (Mustelus henlei) is an epibenthic elasmobranch ranging in shallow waters of the east Pacific Ocean from the Gulf of California to Coos Bay, Oregon, in the northern hemisphere, and from Ecuador to Peru in the southern hemisphere (Love 1996). Brown smoothhounds are found on a 
diversity of substrates along the continental slope, but show a preference for shallow muddy or sandy bays, such as Tomales Bay in northern California, utilizing them for feeding and refuge from larger predators (Love 1996). Throughout their range, Tomales Bay being no exception, brown smoothhounds are known to feed heavily on benthic organisms including crabs, shrimp, and polychaete worms (Haeseker and Cech 1993; Love 1996). Brown smoothhounds remain in bays throughout most of the year, but may leave them during the winter as the waters cool and rains reduce the salinity (Love 1996; Hopkins and Cech 2003).

Prior to this study, two other elasmobranch species had been tracked in Tomales Bay. Coarse-scale, population-based tracking studies indicated that time of day was the most significant influence on the movements of bat ray (Myliobatus californica) [Matern et al. 2000], and that movement direction in leopard sharks (Triakis semifasciata) was related to tide (Ackerman et al. 2000). Fine-scale, individual-based tracking (Klimley et al. 2005) demonstrated that bat rays exhibit two modes of travel: rapid and directional, and slow and non-directional. While some of the bat rays in Klimley et al. (2005) behaved consistently with the behavioral thermoregulation hypothesis presented by Matern et al. (2000), some did not, emphasizing the importance of being cognizant of individual behavior when interpreting the results of population-based telemetry studies. There have been no past studies of the movement patterns of the brown smoothhound.

Our objective was to relate the directionality and rate of movement of brown smoothhounds to environmental variables using both coarse-scale and finescale tracking. Coarse-scale tracking consisted of locating multiple individuals sequentially during an environmental-based sampling period (e.g. day or night, high or low tide), while fine-scale tracking consisted of constantly following a single individual for an extended period while recording the same environmental variables. We reasoned that the movement patterns of brown smoothhounds would resemble those of sympatric leopard sharks because of the overlap in their morphology (Setka and Cech 1994), habitat selection (Love 1996), and food habits (Haeseker and Cech 1993; Webber and Cech 1998). As observed in leopard sharks (Ackerman et al. 2000), we hypothesized that the brown smoothhounds would: (1) move during incoming and high tides towards the inner bay where food would be more available in the submersed littoral zone of the inner bay, and (2) that their rate of movement would be greater during nighttime than during daytime.

\section{Materials and methods}

Study site

We tracked smoothhound sharks in Tomales Bay, located north of San Francisco Bay in Marin County, California. It is a $20-\mathrm{km}$-long straight bay, averaging $1.4 \mathrm{~km}$ in width and $3 \mathrm{~m}$ in depth (Fig. 1). The cumulative area of the bay is ca. $24 \mathrm{~km}^{2}$. The bay has been divided into an inner and outer bay based on physical and chemical characteristics (Smith et al. 1991; Hopkins and Cech 2003). Longitudinal gradients of the physical and chemical properties of the water in Tomales Bay are large relative to lateral and vertical gradients, and vertical stratification is weak (Smith et al. 1991). The water in the shallow inner bay $(12 \mathrm{~km})$ has large seasonal and daily shifts in temperature, whereas the deeper outer bay $(8 \mathrm{~km})$ is more influenced by oceanic conditions and therefore the water temperature remains more constant (Matern et al. 2000). Exchange of water between the inner and outer bay during the summer is minimal, and the inner bay tends to be $2-6^{\circ} \mathrm{C}$ warmer and 1-3 ppt more saline than the outer bay at this time of year (Smith et al. 1991). A deep channel exists on the west side of the outer bay and is flanked by a sandbar, whereas the inner bay consists of extensive expanses of intertidal mud flats (Smith et al. 1991).

Fish collection

We collected six adult brown smoothhounds, one male and five females, on 24-30 June 2004 (Table 1). The sharks were captured using gillnets $(100 \mathrm{~m} \times 3 \mathrm{~m}, 6 \mathrm{~cm}$ stretch mesh) set for 20-60 min perpendicular to the western shoreline of the inner and outer regions of Tomales Bay. We immediately placed captured brown smothhounds into a cooler on the boat with oxygenated sea water until transmitter implantation (5 min-1.5 h).

Transmitter implantation

Each shark was anesthetized by immersion in water saturated with $\mathrm{CO}_{2}$, made by mixing $40 \mathrm{ml}$ concentrated acetic acid and $170 \mathrm{~g}$ sodium bicarbonate into $20 \mathrm{~L}$ of 
Fig. 1 Bathymetric map of Tomales Bay and its position in California

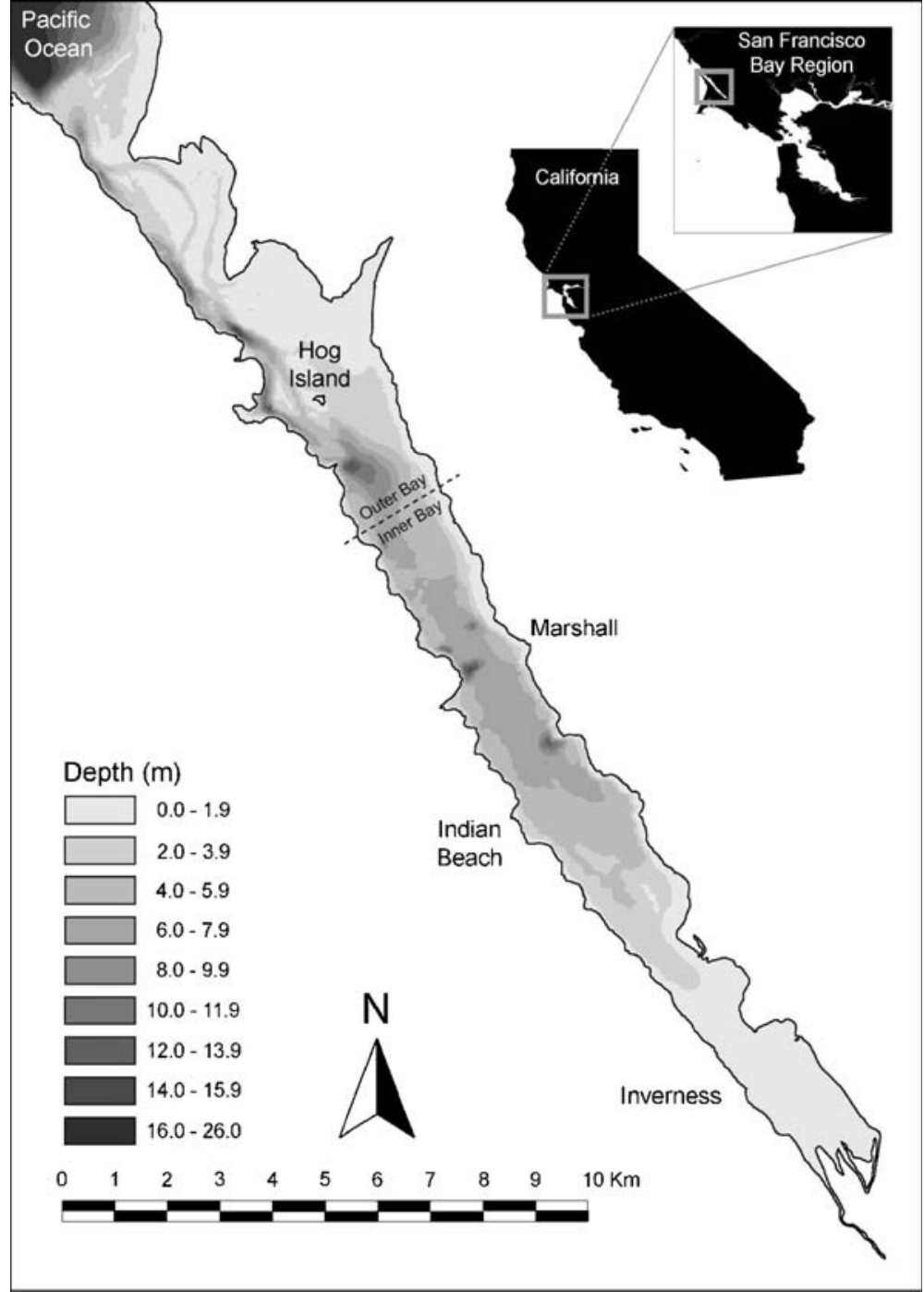

sea water (Peake 1988). Immediately after gill ventilation movements ceased (3-5 min), the shark was removed from the cooler, placed in a supine position on a portable operating table, and gills were irrigated with sea water (alternating, 1-L beakers of water with the anesthetic and sea water). We made a $2.5-\mathrm{cm}$, axial incision adjacent to the ventral midline and inserted an ultrasonic transmitter (Lotek, CAFT16-1), which was

Table 1 Capture information for brown smoothhounds tracked in Tomales Bay. (TL= total length, $\mathrm{M}=$ male, $\mathrm{F}=$ female)

\begin{tabular}{|c|c|c|c|c|c|c|c|}
\hline Date & Shark & Location Captured & Sex & $\mathrm{TL}(\mathrm{cm})$ & Weight (kg) & Time of Catch & Time of Release \\
\hline 24 Jun 2004 & BS1 & N. Indian Beach & $\mathrm{F}$ & 87 & 2.35 & $14: 45$ & $15: 17$ \\
\hline 24 Jun 2004 & $\mathrm{BS} 2$ & S. Indian Beach & $\mathrm{F}$ & 95 & 3.03 & $14: 45$ & $16: 55$ \\
\hline 25 Jun 2004 & BS3 & N. Indian Beach & $\mathrm{F}$ & 86 & 2.41 & $15: 10$ & $15: 40$ \\
\hline 30 Jun 2004 & BS4 & Hog Island & M & 79 & 1.45 & $7: 55$ & $8: 40$ \\
\hline 30 Jun 2004 & BS5 & S. Indian Beach & $\mathrm{F}$ & 74 & 1.22 & $12: 20$ & $13: 30$ \\
\hline 30 Jun 2004 & BS6 & S. Indian Beach & $\mathrm{F}$ & 86 & 2.07 & $12: 20$ & $14: 19$ \\
\hline
\end{tabular}


54-mm long and 16-mm in diameter and weighed $18.9 \mathrm{~g}$ in water, in the peritoneal cavity and closed the incision with silk sutures and cyanoacrylate glue. After the surgery (duration $<10 \mathrm{~min}$ ), we recorded the shark's mass, length, and sex (Table 1). Once the shark recovered from anesthesia, it was immediately released at the capture site. Three days were allowed for the individual to recover from the stress of capture and anesthesia before we began tracking.

\section{Telemetry: coarse-scale}

Coarse-scale tracking was conducted over 2.5 weeks from 29 June to 15 July 2004 during day and night and all tidal stages (incoming, high, outgoing, and low). Each shark's transmitter emitted a unique signal, which was detected by a submerged directional hydrophone (Lotek, LHP-1) attached to the boat gunwale. The signal was converted to a radio frequency by an upconverter (Lotek, UUCN-150) and decoded by a radio receiver (Lotek, SRX-400). The receiver recorded which shark was being tracked and digitally stored its identity and its geographic coordinates obtained from a global positioning system (GPS; Garmin, GPSMAP 76S; 5 m accuracy). The range of transmitter detection was ca. $500 \mathrm{~m}$, depending on ambient noise and the bay's surface conditions. When searching for sharks, transects were made $500 \mathrm{~m}$ offshore along one side of the bay, submerging the hydrophone to search for the transmitters' signal at 500-m distance intervals. Upon detecting a transmitter's signal, we proceeded toward its source until directly overhead, indicated by the strong and non-directional nature of the transmitter's signal (Winter 1996). We then recorded the transmitter's identity, its position, time of day, and measured five hydrographic variables: depth (with a sounding line), substrate (using indicator clay on a sounding-line weight), and salinity, temperature, and dissolved oxygen at the surface and at ca. $3.3 \mathrm{~m}$ depth with a meter and probe (YSI, Model 85). We then left the shark and resumed searching for other individuals. We attempted relocation of each shark multiple times during each sampling session, allowing frequent calculations of movement directions and rates.

Data analysis: coarse-scale

Brown smoothhound positions obtained during coarsescale tracking were projected onto a bathymetric map of
Tomales Bay, using a $5 \mathrm{~m}$ grid digital elevation model. The digital chart was obtained from the GIS Service Center of the Information Technology Division of the California Department of Fish and Game, located in Sacramento, California. The map was displayed on a PC using a geographic information system (GIS) (ESRI, ArcView 3.2), following Klimley et al. (2005).

Tidal stages were determined using tide tables and were split into four stages: incoming, high, outgoing and low. High and low tides were defined as $1 \mathrm{~h}$ before and after the extreme high or low. The diel cycle was split into day and night based on the times of sunrise and sunset according to the U.S. Naval Observatory for Point Reyes Station, California. The distance to the ocean (the mouth of Tomales Bay) was calculated for every shark location using the Geofunc Microsoft Excel add-in. Using SigmaStat 3.5 statistical software (Systat Software, Inc.), two-way ANOVAs were employed to analyze the effects of the diel and tidal cycles on shark distance-to-ocean (ie. movement direction), followed by a Tukey pairwise multiple comparison test when significant differences were detected. To boost our sample size per treatment for the distance-to-ocean analyses we grouped tidal-stage shark positions into high/incoming and low/outgoing stages.

Shark movement rates were calculated by dividing distance traveled between successive positions by the time interval between position readings. The movement rate data was analyzed in $\mathrm{cm} \mathrm{sec}^{-1}$ after a natural-log transformation, but reported in the text as $\mathrm{m} \mathrm{sec}^{-1}$ to aid comprehension. Two-way ANOVAs were then used to analyze differences in movement rates between tidal stages and between diel stages, followed by a Tukey pairwise multiple comparison test when significant differences were detected.

Telemetry: fine-scale

In fine-scale tracking, we continuously tracked a single shark (BS2 or BS3 depending on the tracking session) for two 20-21 h intervals and one 4-h interval over a period from 1-13 July 2004. Tracking intervals were chosen to include as many combinations of tidal and diel stages as possible. After locating our target shark for the tracking session, we positioned our boat directly above it and followed it continuously, recording the time of day and the geographical coordinates every 6-15 min with a few exceptions (i.e. the shark could not be detected or we returned to the dock for refueling/crew 
exchange). During fine-scale tracking sessions, the same five hydrographic variables were measured every hour.

Data analysis: fine-scale

Brown smoothhound positions recorded during finescale tracking were imported into a GIS (ESRI, ArcView 3.2 ) in the same manner described for coarse-scale analysis. In order to describe the general patterns of finescale brown smoothhound movements, consecutive points were selected from each track and classified by polygraphic shape: points in no apparent order, but separated, were classified as continuous, non-uniform swimming (CS) movement; points that were linear were classified as straight-line swimming (SS) movement; points that were very close to one another $\left(<10 \mathrm{~m} \mathrm{~h}^{-1}\right)$ were classified as non-movement (NM). We used software (Oriana 3) to calculate circular statistics that quantified the directionality of the polygraphic shapes in each tracking session, indicated by the coefficient of angular concentration (Rayleigh's ' $r$ '). An $r$ value of 1 indicates maximum directionality, whereas 0 indicates omni-directionality. Furthermore, Rayleigh's uniformity test was used to determine whether the distributions of directional movements were significantly non-uniform. Because of our low, fine-scale tracking sample size $(\mathrm{N}=2)$, we did not analyze the effects of the tidal and diel cycles on the distribution of BS2 and BS3 as we did with our coarse-scale tracking data.

Our methods for computing fine-scale rates of movement and the statistical analyses of these data were the same as described above for the coarse-scale analysis, except that the fine-scale data could not be transformed to fit a normal distribution. Thus, a Kruskal-Wallis ANOVA on ranks was used, followed by Dunn's pairwise multiple comparison test when significant differences were detected. The data from tracks BS3-A and -B were combined before analysis.

\section{Results}

\section{Coarse-scale tracking}

We gathered a total of 121 locations for all six smoothhounds during coarse-scale tracking. Whereas there was no apparent pattern to the sharks' movement directions based on the diel cycle (Fig. 2a), a pattern did exist for

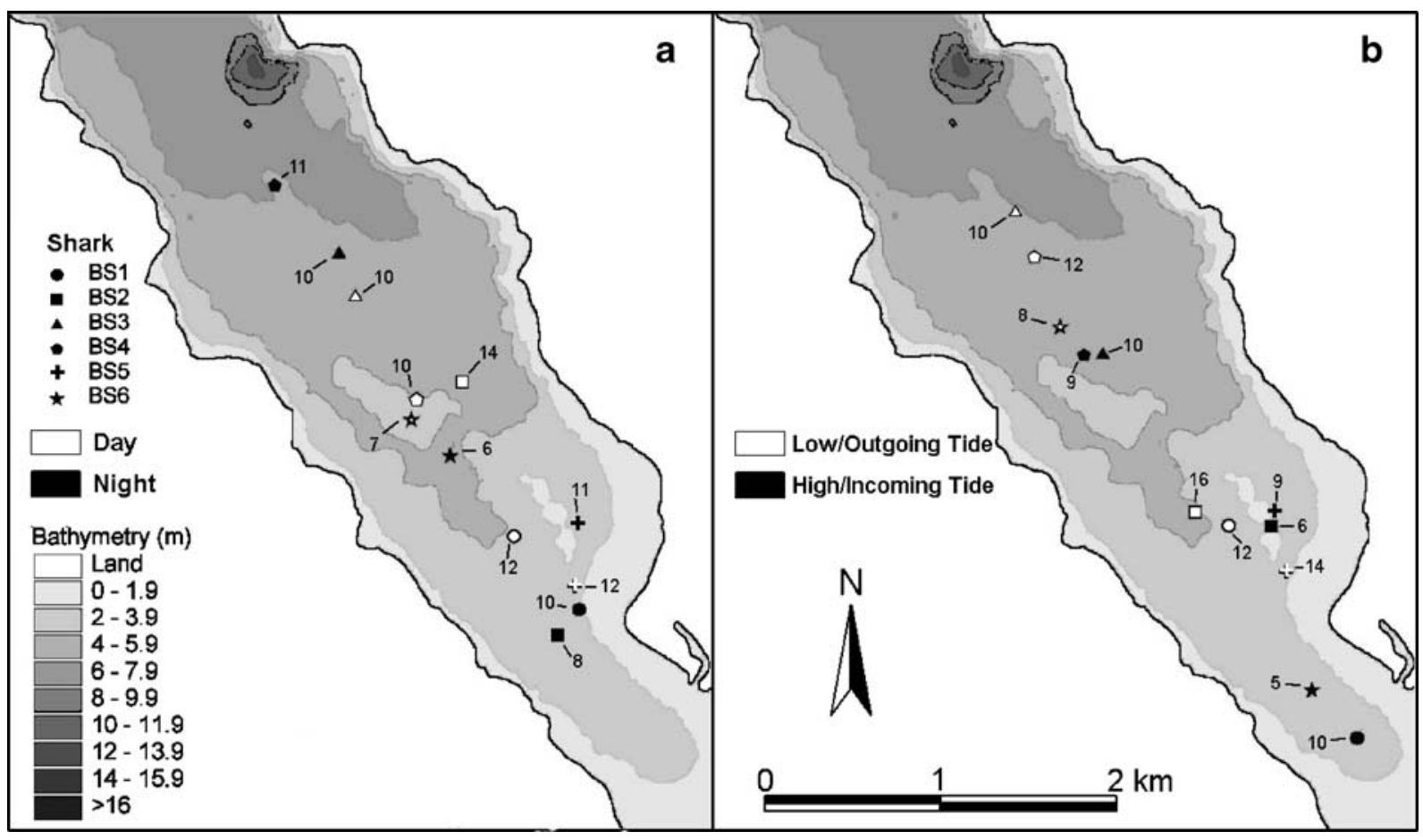

Fig. 2 Mean locations for individual sharks through the diel (on the left; part a) and tidal (on the right; part b) cycles overlain on a bathymetric map of a section of Tomales Bay. The sample size for each symbol is indicated on the map 
Table 2 Two-way ANOVA results from analyses of coarse-scale tracking of brown smoothhound movements in Tomales Bay. Rate of movement (ROM) data were converted to $\mathrm{cm} \mathrm{s}^{-1}$ then natural-log transformed for the analyses. Means reported are least square means. Bold text indicates a statistically significant result.

\begin{tabular}{|c|c|c|c|c|c|}
\hline Tracking Period & $\mathrm{N}$ & Mean ROM $\left(\mathrm{m} \mathrm{s}^{-1}\right)$ & Least Squares Mean $\left[\ln \left(\mathrm{ROM} \mathrm{cm} \mathrm{s}^{-1}\right)\right]$ & F-statistic & P-value \\
\hline Day & 39 & 0.073 & 1.54 & 5.331 & 0.024 \\
\hline Night & 51 & 0.104 & 2.00 & & \\
\hline High Tide & 12 & 0.090 & 2.00 & 5.28 & 0.003 \\
\hline Incoming Tide & 12 & 0.044 & 1.30 & & \\
\hline Low Tide & 17 & 0.052 & 1.28 & & \\
\hline Outgoing Tide & 47 & 0.117 & 2.19 & & \\
\hline Entire & 88 & 0.091 & & & \\
\hline
\end{tabular}

the tidal cycle (Fig. 2b). Mean shark positions were located significantly further from the mouth of the bay during high/incoming tides than during low/outgoing tides $(\mathrm{P}=0.014)$ (Table 3$)$. Though, BS6 was the only individual to exhibit this directional movement at a significant level in Tukey multiple pairwise comparisons ( $\mathrm{P}=0.01$; Table 4).

The sharks' movement rates ranged over $0.01-0.34 \mathrm{~m}$ $\mathrm{sec}^{-1}$, with an overall mean of $0.09 \mathrm{~m} \mathrm{sec}^{-1}$. The sharks exhibited significantly different rates of movement in night $\left(\right.$ mean $\left.=0.10 \mathrm{~m} \mathrm{sec}^{-1}\right)$ vs. day $($ mean $=0.07 \mathrm{~m})$ $(\mathrm{P}=0.024)$ and across the tidal cycle $(\mathrm{P}=0.003)$ (Table 2). However, the only significant difference in movement rates between tidal stages occurred between outgoing and low tides $(\mathrm{P}=0.008)$ and outgoing and incoming tides $(\mathrm{P}=0.029)$ (Table 5). Movement rates between all other tidal combinations were statistically indistinguishable (Table 5). Due to the time gap between positions during coarse-scale tracking, these data represent minimal movement rates.

Table 3 Two-way ANOVA results from analyses of coarse-scale tracking of brown smoothhound movements in Tomales Bay. Rate of movement (ROM) data were converted to $\mathrm{cm} \mathrm{s}^{-1}$ then
Hydrographic gradients we measured were small throughout the study site for the duration of our study. Dissolved oxygen levels (mean: $8.5 \mathrm{mg} \mathrm{O}_{2} \mathrm{~L}^{-1}$ ) were quite homogeneous throughout the bay with the lowest reading (7.5 $\mathrm{mg} \mathrm{O}_{2} \mathrm{~L}^{-1}$ ) being well above stressful levels (Davis 1975; Lai et al. 1990). Similarly, temperature $\left(\right.$ mean $=19.2^{\circ} \mathrm{C}$, range $=17.7-19.9^{\circ} \mathrm{C}$ ), salinity (mean $=34.2 \mathrm{ppt}$, range $=33.8-34.4 \mathrm{ppt}$ ), and substrate composition ( $95 \%$ of measurements were mud) all showed minimal variation within the bay. However, because we only measured these variables in waters used by the sharks and not what was available but not used, we cannot draw any correlations between the movements of the sharks and these hydrographic variables.

\section{Fine-scale tracking}

Two brown smoothhounds were tracked on a fine scale over three tracking periods. BS3 was tracked from 10:15

natural-log transformed for the analyses. Means reported are least square means. Bold text indicates a statistically significant result.

\begin{tabular}{|c|c|c|c|c|c|}
\hline Tracking Period & $\mathrm{N}$ & Mean Distance to Ocean (km) & Least Squares Mean (km) & F-statistic & $\mathrm{P}$-value \\
\hline Day & 66 & 14.65 & 14.62 & 0.002 & 0.962 \\
\hline Night & 55 & 14.56 & 14.61 & & \\
\hline High/Incoming Tide & 44 & 14.93 & 14.93 & 6.174 & 0.014 \\
\hline Low/Outgoing Tide & 77 & 14.42 & 14.33 & & \\
\hline High Tide & 17 & 15.17 & Not Tested & & \\
\hline Incoming Tide & 28 & 14.80 & & & \\
\hline Low Tide & 17 & 14.72 & & & \\
\hline Outgoing Tide & 59 & 14.32 & & & \\
\hline Entire & 121 & 14.61 & & & \\
\hline
\end{tabular}


Table 4 Tukey's test results for the analysis of brown smoothhound positions in the Tomales Bay relative to the tidal cycle. Means reported are least square means. Bold text indicates a statistically significant result. Overall $\mathrm{P}$-value $=$ 0.014. $(\mathrm{H} / \mathrm{I}=$ high/incoming tides, $\mathrm{L} / \mathrm{O}=$ low/outgoing tides $)$

\begin{tabular}{|c|c|c|c|c|}
\hline \multirow[t]{2}{*}{ Shark } & \multicolumn{2}{|c|}{ Mean Distance To Ocean $(\mathrm{km})$} & \multirow[t]{2}{*}{ q-statistic } & \multirow[t]{2}{*}{ P-value } \\
\hline & $\mathrm{H} / \mathrm{I}$ & $\mathrm{L} / \mathrm{O}$ & & \\
\hline BS1 & 15.84 & 14.94 & 2.388 & 0.094 \\
\hline BS2 & 15.56 & 15.03 & 1.06 & 0.455 \\
\hline BS3 & 14.14 & 13.14 & 2.538 & 0.076 \\
\hline BS4 & 13.78 & 13.27 & 1.26 & 0.375 \\
\hline BS5 & 15.44 & 15.62 & 0.493 & 0.728 \\
\hline BS6 & 15.85 & 13.98 & 3.692 & 0.01 \\
\hline
\end{tabular}

to $14: 11$ on 1 July 2004 and from $14: 54$ on 7 July to 11:46 on 8 July 2004. BS2 was tracked from 13:24 on 12 July to $09: 13$ on 13 July 2004 . Both sharks displayed the three patterns previously defined: CS, SS, NM. Figure 3 shows the fine-scale track of BS3 in its entirety, exhibiting examples of all three patterns of movement. We determined the degree of directionality to the segments of the tracks that we segregated into the three categories (Table 6). As expected, no directionality was indicated for the segments of the track exhibiting little movement while more directionality was exhibited while actively swimming. Shark BS2 exhibited no significant directionality to NM1, CS1, and CS2 (Table 6). The same shark showed a significant degree of directionality during SS1 and near-significant directionality during SS2. Similarly, the r-values for SS1 and SS2 were considerably higher than those of NM1, CS1, CS2. BS3 showed no significance in directionality for NM2, CS3, CS4, CS5, or SS3. However, BS3 did show significant directionality during SS4 and SS5. Furthermore, SS4 and SS5 had greater r-values than CS4 or CS5.

Both BS2 and BS3 displayed movement rates drastically higher for nighttime than during daytime, but only BS2 exhibited differences between tidal stages (Table 7). For BS2, movement rates averaged 0.18 and $0.12 \mathrm{~m} \mathrm{sec}^{-1}$ for nighttime and daytime, respectively. For BS3, movement rates averaged $0.20 \mathrm{~m} \mathrm{sec}^{-1}$ and $0.10 \mathrm{~m} \mathrm{sec}^{-1}$ for nighttime and daytime, respectively. BS2's mean movement rates during outgoing and low tides were near equal at $0.19 \mathrm{~m} \mathrm{sec}^{-1}$ and $0.19 \mathrm{~m} \mathrm{sec}^{-1}$, and both were significantly higher than those during incoming tide (O vs. I: Diff of ranks $=28.97$,
$\mathrm{Q}=4.834, P<0.05 ; \mathrm{L}$ vs I: Diff of ranks $=27.81, \mathrm{Q}=$ 3.805, $P<0.05$; O vs. L: Diff. of ranks $=1.16, \mathrm{Q}=$ $0.18, P>0.05$ ). Only one location of BS2 was obtained during high tide, thus, high tide was excluded in the analysis of its movement rates. Unlike BS2, BS3's rates of movement did not differ among tidal stages. Only two locations of BS3 were obtained during low tide, thus, low tide was excluded in the analysis of its rates of movement.

BS2 was located over substrates consisting of mud ( $85 \%$ of samples), gravel/algae $(2 \%)$, mud/algae $(5 \%)$, gravel (5\%), algae (2\%) and sand (1\%) in water column depths of $2.6-4.7 \mathrm{~m}$. At the surface, the salinity recorded over the shark was relatively constant at $34 \mathrm{ppt}$, while dissolved oxygen ranged over $89.2-99.5 \%$ of air saturation, and temperature ranged over $19.3-20.1{ }^{\circ} \mathrm{C}$. At $3.3 \mathrm{~m}$ depth, salinity stayed constant at $34 \mathrm{ppt}$, while dissolved oxygen saturation fluctuated over 88.9$99.8 \%$, and temperature ranged over $19.4-20.1^{\circ} \mathrm{C}$.

BS3 spent $95 \%$ of its time over a muddy substrate and $5 \%$ of its time over a sand/clay substrate in depths ranging from 2.0 to $9.6 \mathrm{~m}$. At the surface, salinity was $34 \mathrm{ppt}$, dissolved oxygen fluctuated over $95.4-101.7 \%$ of air saturation, and temperature ranged over 16.5$19.6^{\circ} \mathrm{C}$. At $3.3 \mathrm{~m}$ below the surface, salinity was $34 \mathrm{ppt}$, dissolved oxygen fluctuated over $95.4-107.0 \%$, and temperature ranged over $16.5-19.4^{\circ} \mathrm{C}$.

\section{Discussion}

Our results from these two, distinct methods of tracking elucidated the complex movement patterns of brown smoothhounds in Tomales Bay, California. For coarsescale tracking data, the tidal cycle appeared to be the

Table 5 Tukey's test results for the coarse-scale rate of movement analysis through the tidal cycle. Overall P-value $=0.003$. Bold text indicates a statistically significant result. $(\mathrm{O}=$ outgoing tide, $\mathrm{L}=$ low tide, $\mathrm{H}=$ high tide, $\mathrm{I}=$ incoming tide)

\begin{tabular}{lcc}
\hline Comparison & q-statistic & P-value \\
\hline O vs. L & 4.676 & $\mathbf{0 . 0 0 8}$ \\
O vs. I & 4.028 & $\mathbf{0 . 0 2 9}$ \\
O vs. H & 0.857 & 0.930 \\
H vs. L & 2.783 & 0.211 \\
H vs. I & 2.504 & 0.297 \\
I vs. L & 0.089 & 1.000 \\
\hline
\end{tabular}




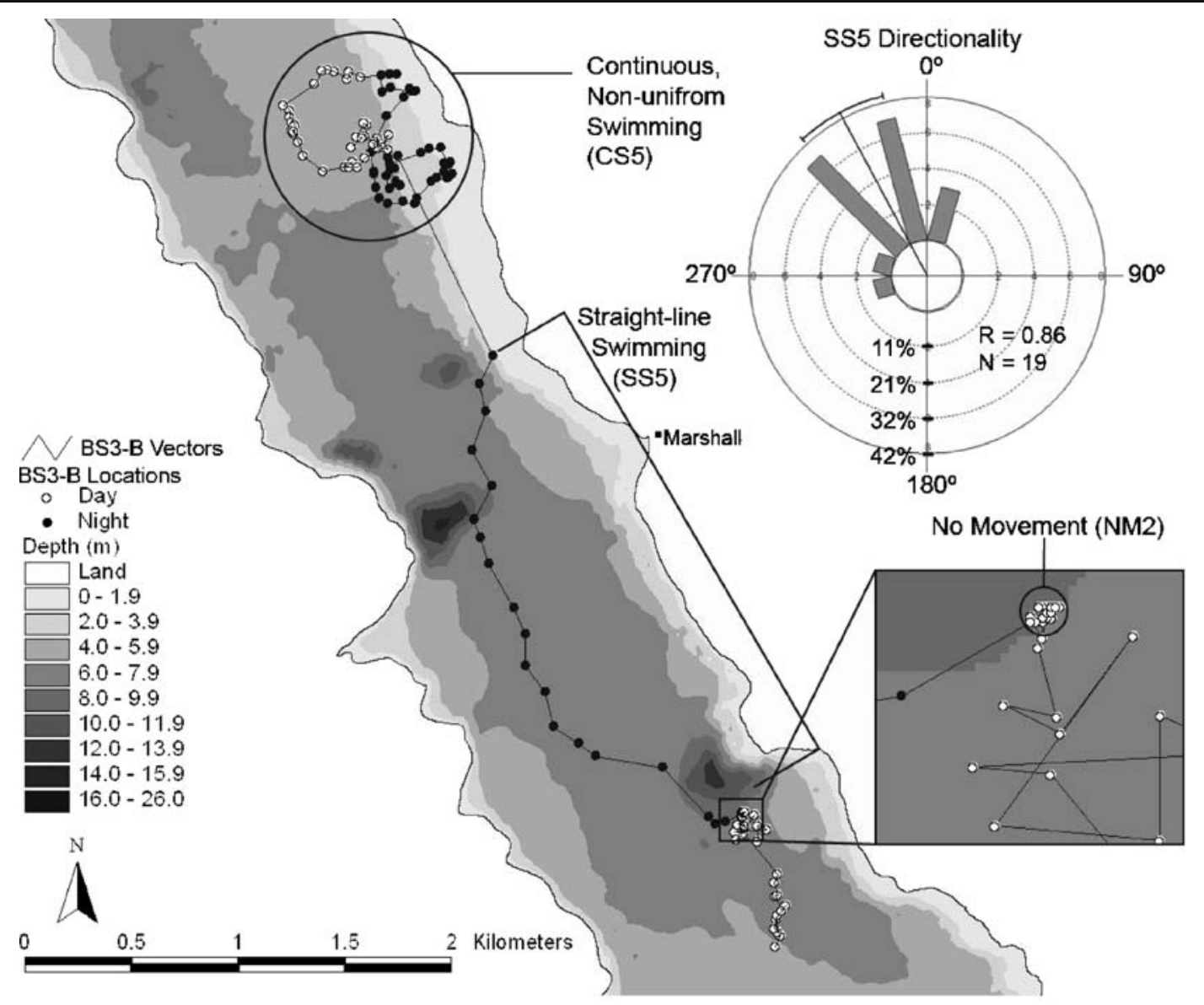

Fig. 3 A fine-scale track of brown smoothhound BS3 in Tomales Bay. Dark circles designate nighttime positions; white circles daytime positions. This figure illustrates all three swimming classifications exhibited during our fine-scale tracking: 1) continuous, non-uniform swimming (CS), 2) straight-line swimming (SS), and 3) no movement (NM). The rectangular inset shows an

dominant factor affecting their distribution, whereas both the diel and tidal cycles affected their movement rates. At the individual level, (i.e. fine-scale tracking) the diel cycle affected the movement rates of both BS2 and BS3, while the tidal cycle influenced the movement rate of only BS2. Their movements were contained within waters with weak temperature, salinity, and dissolved oxygen gradients typical of the inner bay in summer (Smith et al. 1991). Tracking studies of other elasmobranchs in Tomales Bay also endeavored to relate movements to diel and tidal cycles. Matern et al. (2000) found a distinct periodicity to bat rays' movements between the inner bay and the outer bay, hypothesized to be related to the large temperature gradient between the two areas, but their movement expanded view of NM2 when the shark appeared to be motionless. The shark first exhibited Straight-line Swimming (SS5) at sunset during the change of the tide to outgoing. The inlaid circular histogram indicates strong directionality during SS5. The shark performed continuous, non-uniform swimming (CS5) from night to day

rates did not correlate with either diel or tidal cycles. In contrast, Ackerman et al. (2000) found that leopard sharks showed strong movements with tides and increased their movement rates at night compared to day. As hypothesized, the brown smoothhounds displayed similar movement patterns to those of leopard sharks. Interestingly, brown smoothhound and leopard sharks often associate with the same substrates (Love 1996; Ackerman et al. 2000), have similar diet compositions (Haeseker and Cech 1993; Webber and Cech 1998), and share almost identical blood and muscle characteristics (Setka and Cech 1994).

Sharks were located farthest toward the inner bay during high and incoming tides. These movements into freshly flooded mud flats on incoming and high 
Table 6 Directionality of movements for individual brown smoothhounds tracked on a fine scale based on classification of movement polygons. Bold text indicates a statistically significant result. $(\mathrm{A}=$ Day $1, \mathrm{~B}=$ Day 2, $\mathrm{CS}=$ continuous, non-uniform swimming,

$\mathrm{SS}=$ straight-line swimming, $\mathrm{NM}=$ nonmovement, $r=$ Rayleigh's coefficient of angular concentration, $\mathrm{P}=$ probability of uniform distribution)

\begin{tabular}{llrrrr}
\hline Shark and Track & Tracking Period & Time Period & N & r & P \\
\hline BS2 & Entire & $13: 24-9: 13$ & 113 & & \\
& SS1 & $13: 38-14: 42$ & 7 & 0.82 & $\mathbf{0 . 0 0 5}$ \\
& CS1 & $14: 53-16: 50$ & 12 & 0.14 & 0.79 \\
CS2 & $16: 57-1: 54$ & 22 & 0.08 & 0.88 \\
SS2 & $4: 51-6: 32$ & 6 & 0.61 & 0.11 \\
BS3-A & NM1 & $7: 33-9: 13$ & 9 & 0.19 & 0.73 \\
& Entire & $10: 15-14: 11$ & 29 & & \\
BS3-B & $10: 21-11: 51$ & 14 & 0.11 & 0.84 \\
& SS3 & $11: 59-11: 41$ & 14 & 0.3 & 0.30 \\
& Entire & $14: 54-11: 46$ & 201 & & \\
& SS4 & $15: 01-16: 19$ & 12 & 0.53 & $\mathbf{0 . 0 2 9}$ \\
& CS4 & $16: 38-19: 10$ & 29 & 0.13 & 0.61 \\
& NM2 & $19: 16-20: 37$ & 13 & 0.19 & 0.65 \\
& SS5 & $20: 47-23: 28$ & 19 & 0.86 & $<\mathbf{0 . 0 0 1}$ \\
& CS5 & $1: 37-11: 46$ & 80 & 0.05 & 0.85 \\
\hline
\end{tabular}

tides are consistent with what is known about their foraging ecology. Brown smoothhounds are known to feed heavily on benthic organisms including crabs, shrimp, and polychaete worms (Haeseker and Cech 1993; Love 1996), many of which are widely available in the tidal mud flats when they are flooded. As the sharks moved inward and outward they generally swam in shallow water, stayed near shore, and may have been foraging. Alternatively their behavior also may reflect predator avoidance (e.g., minimizing contact with larger sharks). Sevengill sharks are present in the bay and they grow to be twice as long as brown smoothhounds, which have been recorded as their prey (Love 1996).
The similarities in the body design and feeding habits of smoothhounds to other sharks that move with tides supports our findings that brown smoothhound sharks also may move in relation to tidal stage. In temperate, estuarine habitats on the eastern U.S. coast, the dusky shark and the sandbar shark moved predominately in the direction of tidal currents (Huish and Benedict 1978; Medved and Marshall 1983). Ackerman et al. (2000) explained the tidally influenced movement on leopard sharks as a means of reducing energy expenditure. Our findings suggest that brown smoothhounds' movements in Tomales Bay are associated with tide to some degree, but not to the degree of the leopard shark. The movement rates through the
Table 7 Kruskal-Wallis ANOVA on ranks results for the fine-scale tracking of sharks BS2 and BS3 in Tomales Bay. Due to low sample sizes, high tide was excluded in the analysis of movement rates of BS2 and low tide was excluded in the analysis of movement rates of BS3. Bold text indicates a statistically significant result. $(\mathrm{A}=$ Day $1, \mathrm{~B}=$ Day $2, \mathrm{ROM}=$ rate of movement)

\begin{tabular}{|c|c|c|c|c|c|c|}
\hline Shark & Tracking Period & $\mathrm{N}$ & Mean ROM (m/s) & Median ROM (m/s) & H-statistic & P-value \\
\hline \multirow[t]{6}{*}{ BS2 } & Day & 41 & 0.12 & 0.08 & 6.875 & 0.009 \\
\hline & Night & 36 & 0.18 & 0.16 & & \\
\hline & High Tide & 1 & 0.01 & 0.01 & & \\
\hline & Incoming Tide & 20 & 0.05 & 0.01 & 25.36 & $<0.001$ \\
\hline & Low Tide & 16 & 0.19 & 0.14 & & \\
\hline & Outgoing Tide & 40 & 0.19 & 0.16 & & \\
\hline \multirow[t]{6}{*}{$\mathrm{BS} 3-\mathrm{A} \& \mathrm{~B}$} & Day & 106 & 0.10 & 0.08 & 38.176 & $<0.001$ \\
\hline & Night & 61 & 0.20 & 0.18 & & \\
\hline & High Tide & 30 & 0.13 & 0.08 & 1.144 & 0.726 \\
\hline & Incoming Tide & 97 & 0.12 & 0.11 & & \\
\hline & Outgoing Tide & 38 & 0.16 & 0.11 & & \\
\hline & Low Tide & 2 & 0.14 & 0.14 & & \\
\hline
\end{tabular}


tidal cycle observed in this study are more difficult to interpret.

From the coarse-scale data, smoothhounds exhibited a maximum rate of movement on an outgoing tide, mid-range rates of movement during high tide, and minimum rates of movement during incoming and low tide. The observed behavior may perhaps be explained by their foraging ecology. The mid-range rates of movement exhibited during high tides may reflect active foraging behavior over mud flats. During an outgoing tide it may be beneficial to a shark to rapidly move off these flats to avoid being stranded. At low tide brown smoothhounds have generally retreated to deeper water where they may await their next foraging opportunity while digesting their last meal, thus exhibiting slower rates of movement. Looking at the individual level, both sharks we tracked exhibited some patterns not clear at the population level. Although fine-scale tracking likely yielded our most accurate movement rates, our sample sizes across the tidal spectrum were inadequate to fully interpret those results. However, across the diel cycle, our sample size doubled per treatment as treatment variables halved versus the tidal cycle (i.e. day and night), permitting comparison to the coarsescale results.

As we expected, at a coarse-scale, our brown smoothhounds showed a significant increase in their movement rates at night versus day. At a fine scale, the difference in movement rate across the diel cycle was even more distinct. The sharks showed a marked increase in their movement rates at night, with BS2 moving 50\% faster and BS3 moving 100\% faster than during the day. These rates were nearly equivalent to those found in leopard sharks by Ackerman et al (2000). Based on our field observations during both tracking modes, the higher resolution of the individual tracking method seems to be the more accurate and precise measure of the smoothhounds' actual movement rates over the diel cycle.

\section{Movement polygons}

Among the movement patterns obtained from finescale tracking, CS was the most common. Our primary hypothesis for the motive behind this movement pattern was foraging. In our field observations, and when plotted on the bathymetric map, continuous non-uniform swimming was generally displayed just off the shoreline and on mudflats where smoothhounds are known to feed (Haeseker and Cech 1993).

Straight-line (SS) swimming was defined as a period of movement in which individuals showed directionality by a high ' $r$ ' coefficient of concentration. Using fine-scale tracking, Klimley (1993) described highly directional swimming in scalloped hammerhead sharks (Sphyrna lewini) in the Sea of Cortez and in bat rays (Myliobatis californica) in Tomales Bay (Klimley et al. 2005). Regarding the cues that brown smoothhounds use for directing its movement, Tomales Bay's high turbidity precludes effective use of vision for directionality, suggesting cues other than vision are at play. Brown smoothhound SS occurred more often during a moving tide, as opposed to a slack tide, in Tomales Bay (SS1, SS2, SS5), perhaps suggesting the use of rheotactic orientation and passive transport. However, Klimley (1993) showed that the heading of a flow-oriented shark would change unless maintained by forward momentum. Klimley et al. (2005) suggested that bat rays swimming in straight-line manner may have been guided by the strong linear magnetic field that runs parallel with the length of Tomales Bay, which was created by a large geological (San Andreas) fault. It is plausible that brown smoothhounds use the same magnetic cues.

The combination of late maturity, low fecundity, and slow growth in most shark species has made them especially vulnerable to over-exploitation, and shark populations around the world are declining at a rapid rate due to overfishing (Musick 1999). In Tomales Bay, female brown smoothhounds are known to birth young throughout the summer (Hopkins and Cech 2003). A better understanding of the brown smoothhounds' movements provides natural resource managers with more information to aid in managing and protecting California's small commercial fishery for brown smoothhounds. While the small scale of this study precludes a detailed assessment of the environmental variables influencing the movements of brown smoothhounds, it is apparent that variables such as tide and diel cycle influence the distribution of the species within inshore habitats. Further large-scale studies are necessary to tease apart the interactions of brown smoothhounds with their environment and to assess the possible impact of anthropogenic activities. 
Acknowledgements We thank the staff of the UC Davis Bodega Marine Laboratory (especially S. McAffee) for logistical support; D. Kratville, N. Quesenberry, J. Graham, S. Feltman, P. Lin, E. Chen, R. McGraw, and J. Phillips for technical assistance; $\mathrm{V}$. deVlaming for manuscript review; and the Department of Wildlife, Fish and Conservation Biology, the Lloyd Swift Scholarship Fund, and the University of California Agricultural Experiment Station (grant no. $3455-\mathrm{H}$ to JJC) for financial support.

Open Access This article is distributed under the terms of the Creative Commons Attribution Noncommercial License which permits any noncommercial use, distribution, and reproduction in any medium, provided the original author(s) and source are credited.

\section{References}

Ackerman JT, Kondratieff MC, Matern SA, Cech JJ Jr (2000) Tidal influence on spatial dynamics of leopard sharks, Triakis semifasciata, in Tomales Bay, California. Environ Biol Fishes 58:33-43 doi:10.1023/A:1007657019696

Davis JC (1975) Minimal dissolved oxygen requirements of aquatic life with emphasis on Canadian species: a review. $\mathrm{J}$ Fish Res Board Can 32:2295-2332

Haeseker SL, Cech JJ Jr (1993) Food habits of the brown smoothhound shark (Mustelus henlei) from two sites in Tomales Bay. Calif Fish Game 79:89-95

Hopkins TE, Cech JJ Jr (2003) The influence of environmental variables on the distribution and abundance of three elasmobranches in Tomales Bay, California. Environ Biol Fishes 66:279-291 doi:10.1023/A:1023907121605

Huish MT, Benedict C (1978) Sonic tracking of dusky sharks in the Cape Fear River, North Carolina. J Elisha Mitchell Sci Soc 93:21-26

Klimley AP (1993) Highly directional swimming by scalloped hammerhead sharks, Sphyrna lewini, and subsurface irradiance, temperature, bathymetry, and geomagnetic field. Mar Biol (Berl) 117:1-22 doi:10.1007/BF00346421

Klimley AP, Kelly JT, Kihslinger RL (2005) Directional and nondirectional movements of bat rays, Myliobatis californica, in Tomales Bay, California. Environ Biol Fishes 74:79-88 doi:10.1007/s10641-005-3997-3

Lai NC, Graham JT, Burnett L (1990) Blood respiratory properties and the effect of swimming on blood gas transport in the leopard shark Triakis semifasciata. J Exp Biol 151:161-641

Love M (1996) Probably more than you want to know about the fishes of the Pacific coast. Really Big Press, Santa Barbara

Matern SA, Cech JJ Jr, Hopkins TE (2000) Diel movements of bat rays, Myliobatis californica, in Tomales Bay, California: Evidence for behavioral thermoregulation? Environ Biol Fishes 58:173-182 doi:10.1023/A:1007625212099

Medved RJ, Marshall JA (1983) Short-term movements of young sandbar sharks, Carcharhinus plumbeus (Pisces, Carcharhinidae). Bull Mar Sci 33:87-93

Musick JA (1999) Ecology and conservation of long-lived marine animals. Am Fish Sym 23:1-10

Peake S (1998) Sodium bicarbonate and clove oil as potential aneshetics for nonsalmonid fishes. N Am J Fish Manage 18:919-924 doi:10.1577/1548-8675(1998)018<0919: $\mathrm{SBACOA}>2.0 . \mathrm{CO} ; 2$

Setka JD, Cech JJ Jr (1994) Blood and muscle characteristics of leopard shark (Triakis semifasciata) and brown smoothhound (Mustelus henlei). Calif Fish Game 80:89-96

Smith SV, Hollibaugh JT, Dollar SJ, Vink S (1991) Tomales Bay metabolism: C-N-P stoichiometry and ecosystem heterotrophy at the land-sea interface. Estuaries 33:223-257

Webber JD, Cech JJ Jr (1998) Nondestructive diet analysis of the leopard shark from two sites in Tomales Bay, California. Calif Fish Game 84:18-24

Winter JD (1996) Advances in underwater biotelemetry. In: Murphy BR, Willis DW (eds) Fisheries techniques, second edition. American Fisheries Society, Bethesda, p 732 